\title{
The effect of GH replacement therapy on endothelial function and oxidative stress in adult growth hormone deficiency
}

\author{
L M Evans, J S Davies, R A Anderson ${ }^{1}$, G R Ellis ${ }^{1}$, S K Jackson ${ }^{1}$, M J Lewis ${ }^{1}$, M P Frenneaux ${ }^{1}$, \\ A Rees and M F Scanlon \\ Section of Endocrinology, Diabetes and Metabolism and ${ }^{1}$ Cardiovascular Sciences Research Group, University Hospital of Wales, Cardiff, UK \\ (Correspondence should be addressed to L M Evans, Section of Endocrinology, Diabetes and Metabolism, Department of Medicine, University Hospital \\ of Wales, Heath Park, Cardiff CF4 4XW, UK; Fax: +44 2920 744581)
}

\begin{abstract}
Objectives: Controversy persists with regard to the atherogenic risk associated with adult growth hormone deficiency (GHD). Endothelial dysfunction and enhanced oxidative stress are early features of atherogenesis. Therefore, we have studied the effect of three months of low dose GH replacement therapy $(0.03 \mathrm{IU} / \mathrm{kg} /$ day $)$ on these parameters in GHD adults.

Subjects and Methods: Eight hypopituitary GHD adults (4 male, 4 female), who were receiving conventional hormone replacement therapy, were studied before and after 3 months of GH replacement $(0.03 \mathrm{IU} / \mathrm{kg} /$ day $)$. All observations obtained were compared with similar measurements made in 8 matched control subjects. All study subjects were non-smokers, normotensive and gave no personal or family history of premature vascular disease. Endothelial function was assessed using a specialised vessel wall tracking system to measure endothelium-dependent, flow-mediated, brachial artery dilatation (FMD). Measurements were repeated following glyceryl-trinitrate (GTN) (endotheliumindependent dilatation). Oxidative stress was assessed by directly measuring lipid-derived free radicals in venous blood by electron paramagnetic resonance spectroscopy. Fasting lipids, insulin, plasma glucose and IGF-I were also measured at baseline and following GH replacement.

Results: FMD, expressed as a percentage change from resting base-line diameter, was significantly impaired in the pre-treatment GHD patients compared with controls $(3.1 \pm 2.1 \%$ vs $6.1 \pm 0.9 \%$, $P<0.001$; means \pm S.D.) indicating endothelial dysfunction. Significant increase in FMD was noted following GH therapy $(3.1 \pm 2.1 \%$ vs $6.5 \pm 1.9 \%, P<0.001)$. Free radicals (arbitrary units) were elevated in the pre-treatment GHD patients compared with controls $(0.36 \pm 0.09$ vs $0.11 \pm 0.12$, $P<0.05)$ and fell significantly following GH therapy $(0.23 \pm 0.03$ vs $0.36 \pm 0.09, P<0.05)$, although they remained elevated compared with controls. Fasting insulin was significantly higher $(25.9 \pm 18.8$ vs $13.9 \pm 6.7 \mathrm{mu} / \mathrm{l}, P<0.05)$ and IGF-I concentrations lower $(10.8 \pm 4.7$ vs $20.2 \pm 6.3 \mathrm{nmol} / \mathrm{l}$, $P<0.05)$ in the pre-treatment GHD subjects. After treatment there were no changes in insulin concentration, although IGF-I levels were normalised $(10.8 \pm 2.3$ vs $23.6 \pm 11.4 \mathrm{nmol} / \mathrm{l}, P<0.05)$. Conclusions: Endothelial dysfunction and enhanced oxidative stress are features of adult GHD. This study suggests plausible mechanisms underlying any proatherogenic tendency in adult GHD and demonstrates improvement of these factors following $\mathrm{GH}$ replacement.
\end{abstract}

European Journal of Endocrinology 142 254-262

\section{Introduction}

Adult growth hormone deficiency (GHD) may be associated with an increased risk of premature cardiovascular disease (1), although the precise nature and magnitude of any risk remain contentious (2). Adult GHD is associated with several cardiovascular risk factors including altered body composition (3), reduced exercise capacity (4), insulin resistance (5) and dyslipidaemia characterised by small, dense low-density lipoprotein (LDL) particles, decreased high-density lipoprotein (HDL) cholesterol and increased triglyceride levels $(6,7)$.
Recently, abnormal post-prandial lipid profiles (a factor implicated in the pathogenesis of atherosclerosis) have also been described in adult GHD patients (8). However, the mechanisms underlying vascular injury in GHD remain unclear, with some authors suggesting that nonphysiological hormone replacement may be of greater significance than GH deficiency per se (9). Intervention studies with recombinant human growth hormone (rhGH) appear to show physical, biochemical and psychological benefits (9) but any effects of rhGH replacement on cardiovascular mortality are hitherto unknown. 
Endothelial dysfunction (ED), which promotes an environment of thrombogenesis and increased vascular resistance, is an early and potentially reversible event in the complex process of atherogenesis (10). ED results in a diminished endothelial capacity to synthesise and release nitric oxide (NO) or an increased destruction of NO after release. NO reduces platelet adhesion, inhibits vascular smooth muscle proliferation and migration (10) and reduces lipoxygenase activity (11), which lowers the amount of oxidised LDL available for uptake by macrophages to form foam cells. NO also has a critical role in regulating local arterial tone. NO released from endothelial cells as a result of agonist stimulation or increased flow $(12,13)$, acts directly on local smooth muscle causing relaxation and thus vasodilatation.

Oxidative stress represents a pathophysiological mechanism that stems from a state of disequilibrium between free radical production and natural antioxidant defences. Free radicals are a by-product of normal energy metabolism and are produced in vivo by phagocytes, endothelial cells, fibroblasts and myocytes (14). When produced in excess of antioxidant capacity, they have a number of damaging effects including cell membrane lipid peroxidation and lipoprotein peroxidation (15). Free radicals derived from lipid peroxidation can inhibit cellular processes and react rapidly with nitric oxide, thus increased oxidative stress reduces the bioavailability of NO and may contribute directly to the pathogenesis of ED (16).

Therefore, enhanced oxidative stress is potentially important in the process of atherogenesis and has been demonstrated in patients with premature atherosclerosis and congestive heart failure $(17,18)$. In order to study the pathogenesis of atherosclerosis in adult GHD and to evaluate the potential impact of GH therapy on the incidence of atherosclerotic disease in these patients, we have measured both oxidative stress and endothelial function in a group of GHD patients before and after GH replacement therapy. We used a non-invasive, direct and fully validated (19) technique of assessing endothelial function in systemic arteries. High-resolution ultrasound is used to measure changes in vessel diameter in response to increased flow (endotheliumdependent dilatation) and sublingual glyceryl-trinitrate (GTN) (endothelium-independent dilatation). To detect and identify reactive lipid-derived free radicals, an ex vivo spin trapping method was used with electron paramagnetic resonance (EPR) spectroscopy. Using these techniques, we have evaluated the effect of $\mathrm{GH}$ replacement therapy in adult GHD patients on factors which are potentially important in the process of atherogenesis in adult patients with GHD.

\section{Materials and methods}

\section{Patients}

Endothelial function and oxidative stress were studied in $8 \mathrm{GH}$ deficient hypopituitary subjects (4 male, 4 female), aged 26-54 years, and 8 age- and sex-matched controls. All subjects were life-long non-smokers, normotensive, normocholesterolaemic and non-diabetic. Each subject had a normal resting electrocardiogram and gave no personal or family history of premature vascular disease. The diagnosis of severe GHD was confirmed by a peak $\mathrm{GH}$ response of $<5 \mathrm{mU} / \mathrm{l}$ following insulin-induced hypoglycaemia (nadir plasma glucose $<2 \mathrm{mmol} / \mathrm{l}$ ). All subjects had been $\mathrm{GH}$ deficient for at least 24 months (mean duration $6.5 \pm 3.5$ years) prior to inclusion in the study. Each subject had been receiving full, stable conventional hormone replacement (hydrocortisone $10 \mathrm{mg}$ bd, thyroxine 75-150 $\mu \mathrm{g}$ daily, i.m. testosterone $250 \mathrm{mg}$ monthly or transdermal oestrogen with daily progesterone), for at least 6 months prior to inclusion in the study, such that target hormone levels were maintained within the normal reference range. In addition, no patient had an original diagnosis associated with increased vascular risk (e.g. acromegaly or Cushing's disease). Control subjects were non-smokers with no personal or family history of premature vascular disease, and comprised healthy volunteers from the staff at the University Hospital of Wales, Cardiff. Control subjects were selected such that both GHD and control groups were matched for age, sex, body mass index, blood pressure and serum cholesterol. The local ethics committee approved the study and each subject gave fully informed, written consent. Each subject was studied at baseline with repeat measurements after 3 months of GH treatment at an initial dose of $0.015 \mathrm{IU} / \mathrm{kg} /$ day during the first month, increased thereafter to $0.03 \mathrm{IU} / \mathrm{kg} /$ day for the subsequent two months. Patients were instructed to make no lifestyle changes, particularly with regard to exercise, during the study.

\section{Measurement of endothelial function}

Flow-mediated dilatation (FMD) was measured by an ultrasonic vessel wall-tracking system as previously reported and validated (19). The system comprises a specially adapted duplex colour flow echo machine (Diasonics Spectra) with a 7.5 MHz linear phased-array transducer (giving high axial resolution), a personal computer, and a $4 \mathrm{Mb}$ high-speed memory. The brachial artery is identified using the ultrasound transducer and anatomical landmarks identified to allow repeat studies. A stand-off device containing ultrasoundcoupling gel prevents compression of the anterior wall of the artery. The transducer is held in a stereotactic clamp and a two-dimensional longitudinal B-mode image of the brachial artery obtained. The radio frequent (RF) signals (sampling frequency $1 \mathrm{kHz}$ ) from the M-mode output are digitised and relayed to the wall tracking system (Vadirec, Arnhem Medical Systems, Arnhem, The Netherlands). On completion of 10-s data acquisition the RF signal is displayed so that the position of the anterior and posterior vessel walls on the RF 
signal can be identified and marked. Vessel wall movements are tracked using the stored RF signals to produce displacement waveforms of the anterior and posterior vessel walls together with the distension waveform (diameter change as a function of time) (19). The distension waveform enables measurement of 'end-diastolic' diameter for each beat (theoretical resolution $\pm 3 \mu \mathrm{m})$.

Blood pressure was recorded throughout the study by photo-plethysmography (Finapres, Omehda, Brussels, Belgium) from a finger cuff on the middle finger of the ipsilateral arm. Blood flow was measured throughout the study using an $8 \mathrm{MHz}$ continuous wave Doppler probe mounted at an angle of $60^{\circ}$ in a Perspex block and positioned over the brachial artery distal to the $7.5 \mathrm{MHz}$ probe. The Doppler signals were analysed by a spectrum analyser (SciMed Dopstation) and stored on a metal audiotape using a high performance recorder (Nakamichi B-100E). Brachial artery blood flow was calculated by multiplying the mean blood velocity (corrected for Doppler angle) by the internal brachial artery diameter measured by wall tracking. Using this technique, the intra-observer coefficient of variation in measuring baseline arterial diameter for our group is $1.6 \%$ (19).

\section{Measurement of venous free radicals}

Reactive free radicals decay too quickly to be observed directly by EPR spectroscopy under normal laboratory conditions. However, they may be 'trapped' by some chemicals ('spin traps') to form long-lived stable radical adducts which can be observed and identified by EPR spectroscopy. While such spin traps are too toxic to be injected into humans, they can be conveniently used to trap free radicals in blood samples ex vivo. This technique has recently been used and validated to identify lipid-derived free radicals generated postexercise in humans (20), and in the coronary sinus of patients undergoing elective cardioplegia (21) and coronary angioplasty (22). Measurement of lipidderived free radicals $e x$ vivo in venous blood was performed in a fasting state at $0900 \mathrm{~h}$ in all subjects. Venous blood $(2.0-2.5 \mathrm{ml})$ was taken directly into a vacuum-sealed glass tube (vacutainer), containing $1 \mathrm{ml}$ of the spin trap, $\alpha$-phenyl N-tert-butyl nitrone (PBN) $(0.125 \mathrm{~mol} / \mathrm{l})$ in saline. These samples were centrifuged at 2000 r.p.m. for $5 \mathrm{~min}$ and the supernatant removed from the packed cells into a clean glass test tube. The PBN adduct was extracted twice from the supernatant with an equal volume of toluene, and concentrated to virtual dryness under nitrogen gas. The resulting yellow oil was redissolved in $100 \mu \mathrm{l}$ pure chloroform and analysed by EPR spectroscopy. Samples were sealed in Pasteur pipettes and measured on a Varian E104 EPR spectrometer operating at $9.1 \mathrm{GHz}$. Typical spectrometer settings were $10 \mathrm{~mW}$ power, 1 Gauss modulation, 0.25 s time constant and 100 Gauss scan range.
EPR spectral parameters were obtained from data acquisition and processing using in-house computational software. EPR spectral peak heights were taken as a good correlation of spin-adduct concentration after confirmation of peak to peak line width conformity and double integration on selected samples. The separation between sets of peaks in the EPR spectrum (coupling constant) was used to identify the trapped lipid radical species. Measurement values of venous free radicals are expressed in arbitrary units.

\section{Biochemistry}

Various metabolic factors implicated in the pathogenesis of ED were measured. Fasting venous blood was drawn following a 12-h overnight fast to enable measurement of insulin-like growth factor (IGF)-I, lipid profiles, glucose and plasma insulin. Total cholesterol and triglyceride concentrations were measured enzymatically using standard techniques $(23,24)$. HDL concentrations were measured after precipitation of apolipoprotein B with phosphotungstate/magnesium (25). LDL was calculated using the Friedewald equation (26). IGF-I was measured after prior acid-ethanol extraction by polyethylene glycol-assisted second antibody radioimmunoassay (27). Plasma insulin was measured by a commercial radioimmunoassay (INSRIA-100, Medgenix Diagnostics, Brussels, Belgium). Plasma glucose was measured by a hexokinase based technique.

\section{Study protocol}

All studies were performed in the morning, following a 12-h overnight fast, in a temperature-controlled room $\left(21^{\circ} \mathrm{C}-23^{\circ} \mathrm{C}\right)$. Fasting venous blood was drawn to enable biochemical analyses and free radical estimation. Venepuncture was conducted after the patient had been in a supine position for $15 \mathrm{~min}$, to reduce any possible confounding effects of exertion on free radical release. Furthermore, each subject was asked to refrain from any excessive physical exertion in the 24-h period immediately prior to the study day, thus further limiting any potential confounding effects of exercise on free radical generation. Baseline measurements of arterial diameter and baseline blood flow were made following $15 \mathrm{~min}$ of supine rest. Further measurements were made during hand hyperaemia, and after sublingual GTN - an endothelium-independent vasodilator.

A paediatric sphygmomanometer cuff was inflated at the wrist to suprasystolic pressure (systolic pressure $+50 \mathrm{mmHg}$ ) for $5 \mathrm{~min}$. Blood flow was recorded from $15 \mathrm{~s}$ before until $90 \mathrm{~s}$ after cuff release, internal brachial artery diameter was measured for $10 \mathrm{~s}$ at 60 , 120,180 , and $300 \mathrm{~s}$ after cuff release. All measurements were repeated 15 min later when values reached original baseline levels. Measurements were repeated 3 min after sublingual GTN spray $(400 \mu \mathrm{g})$ to provide 
Table 1 Pituitary hormone deficiencies, peak GH response, and duration of GHD and original diagnosis.

\begin{tabular}{|c|c|c|c|c|c|c|}
\hline $\begin{array}{l}\text { Age } \\
\text { (years) }\end{array}$ & Sex & Original diagnosis & $\begin{array}{c}\text { Duration of GHD } \\
\text { (years) }\end{array}$ & $\begin{array}{c}\text { IGF-I } \\
(\mathrm{nmol} / \mathrm{I})\end{array}$ & $\begin{array}{l}\text { Peak GH response } \\
(\mathrm{mU} / \mathrm{l})\end{array}$ & $\begin{array}{l}\text { Pituitary hormone } \\
\text { deficiencies }\end{array}$ \\
\hline 26 & $M$ & NFPT & 5 & 12.2 & 1.4 & ACTH, TSH, LH, FSH \\
\hline 56 & $\mathrm{M}$ & NFPT & 15 & 9.4 & 1.3 & ACTH, TSH, LH, FSH \\
\hline 49 & $\mathrm{~F}$ & Apoplexy & 10 & 13.1 & 2 & ACTH, TSH, LH, FSH \\
\hline 38 & $\mathrm{~F}$ & NFPT & 4 & 11.4 & 1.6 & ACTH, TSH, LH, FSH \\
\hline 33 & $\mathrm{~F}$ & NFPT & 3 & 10.2 & 0.5 & ACTH, TSH, LH, FSH \\
\hline 39 & $M$ & NFPT & 12 & 8.3 & 2.7 & ACTH, TSH, LH, FSH \\
\hline 46 & $\mathrm{M}$ & Prolactinoma & 4 & 7.9 & 1.4 & ACTH, TSH, LH, FSH \\
\hline 54 & $\mathrm{~F}$ & NFPT & 7 & 14.1 & 2 & ACTH, TSH, LH, FSH \\
\hline
\end{tabular}

$\mathrm{NFPT}=$ non-functioning pituitary tumour; $\mathrm{ACTH}=$ adrenocorticotrophin; $\mathrm{TSH}=$ thyrotrophin; $\mathrm{LH}=$ luteinising hormone; $\mathrm{FSH}=$ folliclestimulating hormone.

a measure of endothelium-independent vasodilatation. These measurements were carried out at the beginning of the study and were repeated after a 3-month period of $\mathrm{GH}$ replacement.

\section{Statistics}

Descriptive data are expressed as means \pm standard deviation (s.D.). The hypopituitary and control groups were compared using independent two sample $t$-tests. Paired $t$-test was used to analyse changes within individuals as a result of $\mathrm{GH}$ therapy. Relationships between endothelial function, oxidative stress and various metabolic parameters were analysed using univariate and multivariate analyses. Statistical significance was inferred at $P<0.05$.

\section{Results}

\section{Patient characteristics}

Table 1 illustrates the original diagnosis, duration of GHD, the peak GH response to hypoglycaemia and other pituitary hormone deficiencies. Table 2 illustrates the demographic features of both control and GHD subjects. All patients had multiple pituitary hormone deficiencies, which were adequately replaced with hydrocortisone, thyroxine, sex steroids and desmopressin where appropriate (all female subjects were taking standard hormone replacement therapy in the form of combined oestrogen/progestogen preparations). All target hormones were maintained within the normal reference range for at least six months prior to inclusion in this study and therapy remained unchanged during the course of the study. The peak GH responses to insulininduced hypoglycaemia demonstrate that these subjects were severely $\mathrm{GH}$ deficient prior to inclusion in the study.

\section{Metabolic and free radical data}

Table 3 illustrates the metabolic and free radical data in both control and GHD study groups before and after GH replacement therapy. Total cholesterol, LDLcholesterol, HDL-cholesterol and plasma triglyceride were similar in the control and GHD groups and did not change significantly in the latter following $\mathrm{GH}$ therapy. Thyroxine $\left(\mathrm{T}_{4}\right)$, tri-iodothyronine $\left(\mathrm{T}_{3}\right)$, testosterone, oestradiol and plasma glucose concentrations were similar in both control and study groups irrespective of GH therapy. However, fasting insulin levels were significantly elevated in the hypopituitary subjects prior to GH replacement and remained significantly elevated after three months of low dose GH therapy. As expected, the GHD patients had significantly lower IGF-I levels which increased to within the age-related normal range for all patients following $\mathrm{GH}$ replacement. Analysis of the EPR spectra from spin-trapped radicals

Table 2 Demographic features of control subjects and GHD patients. Values are means \pm S.D.

\begin{tabular}{lcc}
\hline & GHD patients & Control subjects \\
\hline Age (years) & $47.1 \pm 5.7$ & $45.7 \pm 4.8$ \\
Sex (M/F) & $4 / 4$ & $4 / 4$ \\
Number & 8 & 8 \\
Height $(\mathrm{cm})$ & $173.1 \pm 6.2$ & $171.5 \pm 8.5$ \\
Weight $(\mathrm{kg})$ & $81.3 \pm 6.4$ & $79.9 \pm 5.8$ \\
Systolic blood pressure $(\mathrm{mm} / \mathrm{Hg})$ & $135.8 \pm 10.6$ & $132.9 \pm 12.8$ \\
Heart rate (beats/min) & $72.1 \pm 6.3$ & $73.9 \pm 7.9$ \\
\hline
\end{tabular}


Table 3 Free radical and metabolic data from the control subjects and GHD patients before and after 3 months of $\mathrm{GH}$ replacement. Results are expressed as means \pm S.D.

\begin{tabular}{|c|c|c|c|}
\hline & Control & Pre GH & Post GH \\
\hline Insulin (mU/I) & $13.9 \pm 6.7$ & $25.9 \pm 18.8^{*}$ & $29.2 \pm 12.9^{\star \star}$ \\
\hline Glucose $(\mathrm{mmol} / \mathrm{l})$ & $5.0 \pm 1.0$ & $5.1 \pm 1.7$ & $5.1 \pm 0.9$ \\
\hline Cholesterol $(\mathrm{mmol} / \mathrm{l})$ & $5.8 \pm 0.5$ & $6.0 \pm 1.1$ & $5.9 \pm 1.0$ \\
\hline Triglyceride $(\mathrm{mmol} / \mathrm{l})$ & $1.3 \pm 0.3$ & $1.4 \pm 0.3$ & $1.4 \pm 0.2$ \\
\hline LDL-cholesterol $(\mathrm{mmol} / \mathrm{l})$ & $3.5 \pm 0.9$ & $3.6 \pm 0.9$ & $3.5 \pm 0.8$ \\
\hline HDL-cholesterol (mmol/l) & $1.3 \pm 0.3$ & $1.2 \pm 0.2$ & $1.3 \pm 0.2$ \\
\hline IGF-I (nmol/I) & $26.2 \pm 6.3$ & $10.8 \pm 2.3^{*}$ & $29.2 \pm 12.9 \dagger$ \\
\hline Free $_{3}(\mathrm{pmol} / \mathrm{l})$ & $4.5 \pm 1.2$ & $4.8 \pm 1.1$ & $4.7 \pm 1.5$ \\
\hline Free $\mathrm{T}_{4}(\mathrm{pmol} / \mathrm{l})$ & $15.8 \pm 2.7$ & $15.3 \pm 2.9$ & $16.1 \pm 1.6$ \\
\hline Testosterone $(\mathrm{nmol} / \mathrm{l})$ & $22.7 \pm 6.1$ & $22.1 \pm 5.3$ & $22.9 \pm 4.8$ \\
\hline Oestradiol (nmol/l) & $233 \pm 161$ & $255 \pm 114$ & $241 \pm 136$ \\
\hline
\end{tabular}

${ }^{*} P<0.05$ Control vs Pre-treatment GHD patients; ${ }^{* *} P<0.05$ control vs post-treatment GHD patients; $\uparrow P<0.05$ Pre-treatment vs post-treatment GHD patients.

derived from venous blood samples, suggested that the radicals trapped were alkoxyl radicals (coupling constants $\mathrm{aN}=13.9$ Gauss, $\mathrm{a} \beta \mathrm{H}=2.2$ Gauss) and carbon-centred radicals $(\mathrm{aN}=14.1$ Gauss; $\mathrm{a} \beta \mathrm{H}=4.0$ Gauss). These assignments, which agree with previous studies (21), suggest that these radicals are derived from decomposition of lipid hydroperoxides in the extracellular compartment after primary free radicalmediated damage. Free radical status as assessed by measuring EPR peak spectral heights was significantly higher in the GHD subjects at baseline, falling significantly following three months of GH replacement but still remaining elevated compared with the control subjects (Fig. 1).

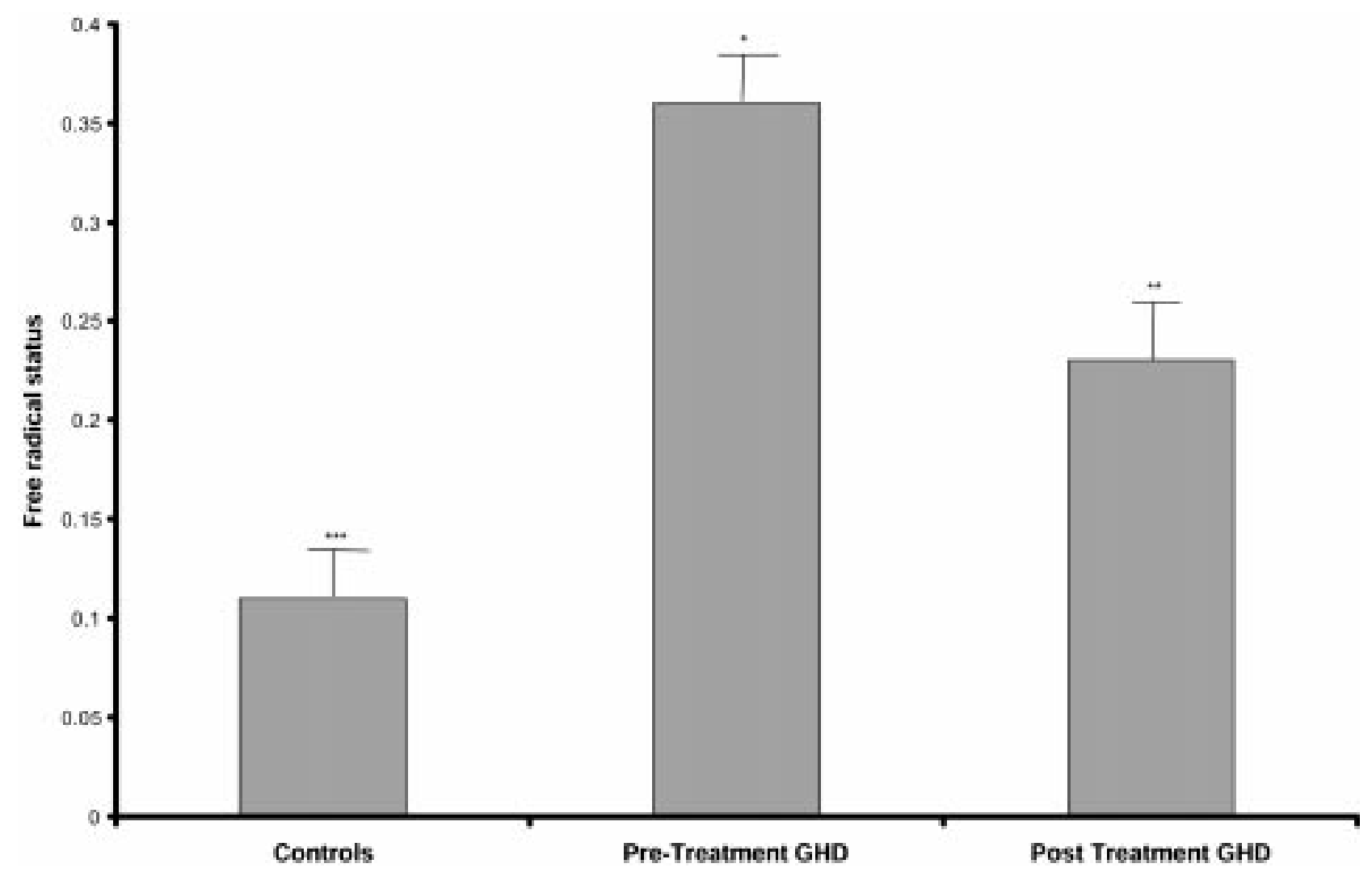

Figure 1 Oxidative stress in control subjects and GHD patients before and after GH replacement. Results are means \pm S.E. ${ }^{\star} P<0.05$ controls vs pre $\mathrm{GH},{ }^{* \star} P<0.05$ pre $\mathrm{GH}$ vs post $\mathrm{GH},{ }^{* \star *} P<0.05$ controls vs post $\mathrm{GH}$. 
Table 4 Vascular data obtained from control subjects and GHD patients at baseline and after GH therapy. Results are expressed as means \pm S.D.

\begin{tabular}{lccc}
\hline & Control & $\begin{array}{c}\text { GHD patients } \\
\text { pre-treatment }\end{array}$ & $\begin{array}{c}\text { GHD patients following } \\
\text { GH therapy }\end{array}$ \\
\hline Diastolic blood pressure $(\mathrm{mm} / \mathrm{Hg})$ & $72.5 \pm 6.9$ & $70.1 \pm 7.9$ & $72.9 \pm 7.4$ \\
Vessel diameter $(\mathrm{mm})$ & $3.57 \pm 0.41$ & $3.61 \pm 0.38$ & $3.59 \pm 0.45$ \\
Resting blood flow $(\mathrm{ml} / \mathrm{min})$ & $232 \pm 21$ & $227 \pm 32$ & $237 \pm 26$ \\
Hyperaemic flow $\%$ increase from baseline) & $393 \pm 21$ & $387 \pm 19$ & $370 \pm 26$ \\
FMD (\% change from baseline) & $6.1 \pm 0.9^{*}$ & $3.1 \pm 2.1 \dagger$ & $6.5 \pm 1.9$ \\
GTN-mediated dilatation (\% change from baseline) & $12.1 \pm 1.8$ & $11.3 \pm 1.5$ & $11.8 \pm 2.4$ \\
\hline
\end{tabular}

${ }^{\star} P<0.05$ Controls vs pre-treatment GHD patients; $\uparrow P<0.05$ Pre-treatment GHD patients vs post-treatment GHD patients.

\section{Vascular data}

Table 4 illustrates the vascular data in the control and study groups both before and after GH replacement. Results were calculated as actual values but are expressed as percentage change from resting baseline values. There were no differences in baseline blood flow, hyperaemic blood flow or resting vessel calibre between patients and controls both before and after $\mathrm{GH}$ therapy. Endothelium-independent GTN-mediated brachial artery dilatation was also similar in both groups irrespective of GH replacement. Peak flow-mediated endothelium-dependent vasodilatation, occurring at 1 min post-cuff release, and thus a measure of endothelial function, was significantly impaired in the pre-treatment GHD patients compared with controls. Furthermore, the impairment in flow-mediated dilatation was maintained at both 2 and $3 \mathrm{~min}$ post-cuff release (Fig. 2). Following GH therapy, however, peak flow-mediated brachial artery dilatation improved significantly in the GHD patients, such that there was no difference in comparison with controls at $1 \mathrm{~min}$. Similarly, FMD at 2 and 3 min post-cuff also significantly improved to a level comparable with controls

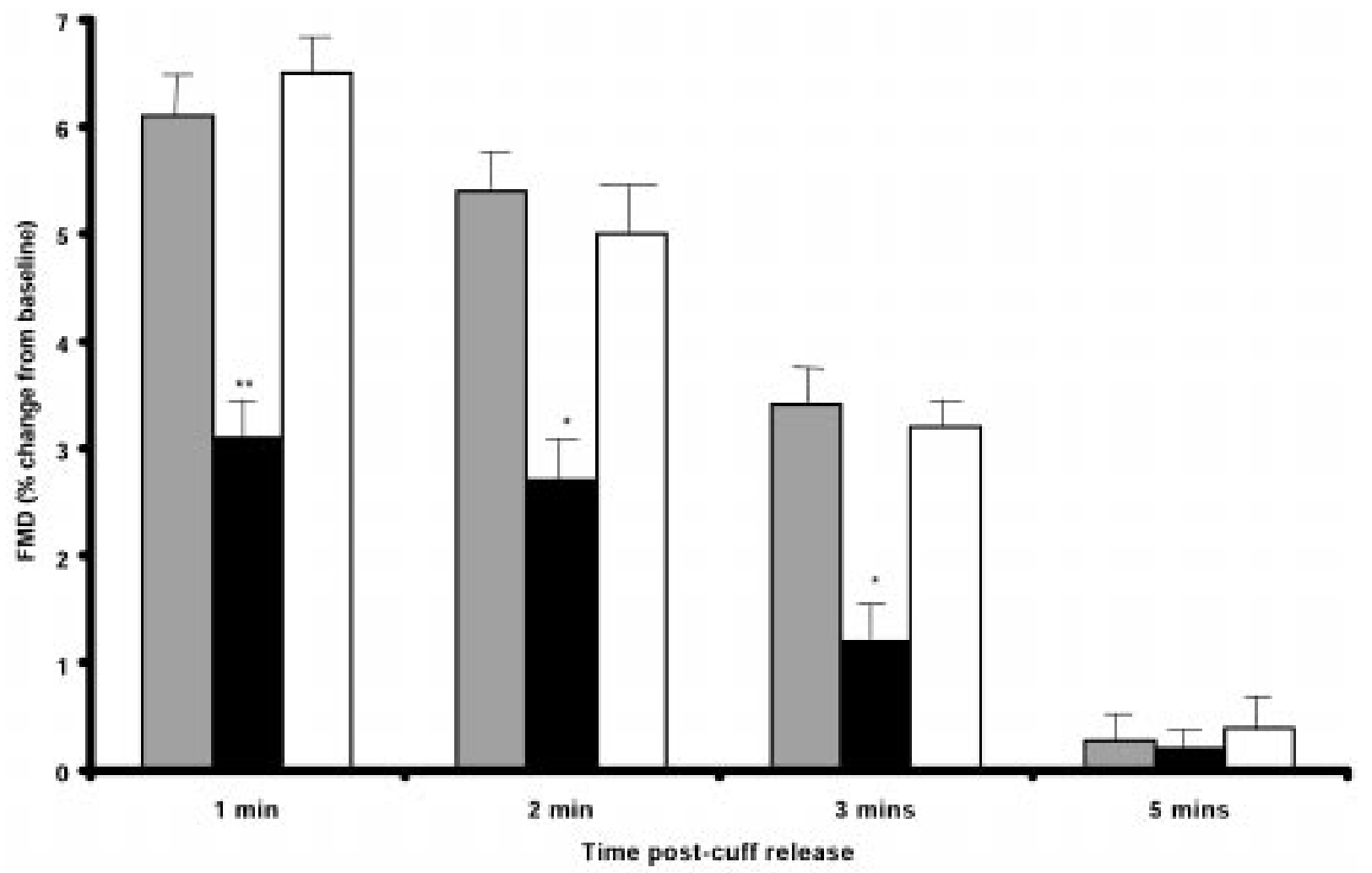

Figure 2 Relationship between time and flow-mediated brachial artery dilatation in GHD adults before and after GH replacement and matched control subjects. Shaded bars, control subjects; solid bars, pre GH replacement; open bars, post GH replacement. Results are means \pm S.E. ${ }^{*} P<0.05,{ }^{*} P<0.001$ vs controls. 
(Fig. 2). Of the other measured parameters in the pre-treatment GHD patients, plasma LDL-cholesterol demonstrated the strongest correlation with FMD, exhibiting an inverse correlation $(r=-0.61, P=0.09)$ which, in view of the relatively small numbers of subjects involved in the study, did not reach statistical significance. Similarly, following GH therapy plasma LDL remained as the strongest, although non significant, predictor of FMD $(r=-0.56, P=0.1)$.

\section{Discussion}

We have demonstrated that peak FMD, a measure of endothelial function, was significantly reduced in the GHD adults compared with matched healthy controls, whereas dilatation in response to GTN was normal. The stimulus of increased blood flow causes a sheer stress on the endothelium resulting in the release of NO, which acts on local vascular smooth muscle to cause vasodilatation. GTN, by contrast, donates NO directly to vascular smooth muscle, thus causing vasodilatation by an endothelium-independent mechanism. The observation of impaired FMD with preserved GTNmediated dilatation indicates a state of endothelial dysfunction in GHD patients. Furthermore, FMD was also reduced at 2 and $3 \mathrm{~min}$ post-wrist-cuff release, further indicating endothelial dysfunction rather than delayed vascular smooth muscle responsiveness to NO. Impaired FMD with preserved GTN-mediated endothelium-independent dilatation is well described in the presence of both overt vascular disease and many identified vascular risk factors $(13,28)$. Since GTN donates NO directly to vascular smooth muscle, then GTN causes vasodilatation irrespective of endothelial integrity, as this is an endothelium-independent mechanism.

At baseline, the GHD patients had significantly higher levels of free radicals as measured by EPR spectroscopy in comparison with control subjects. From analysing coupling constants, the EPR spectra obtained appear to represent both lipid alkoxyl and carbon-centred radicals. Detection of secondarily formed lipid free radicals strongly supports the presence of peroxidative damage in these patients. This suggests that there is a milieu of increased oxidative stress in these patients leading to a proatherogenic diathesis.

Following three months of GH therapy, FMD improved significantly in the GHD subjects to a level comparable with controls at 1,2 and 3 min post-cuff release, whereas GTN responsiveness was unchanged. Hence, GH therapy restored endothelial function to normal in the GHD adults. Oxidative stress also improved significantly with GH treatment but remained elevated compared with control subjects. No gender differences in either FMD or oxidative stress were noted in the GHD subjects following GH replacement. This study, however, comprised a relatively small number of subjects and any potential gender differences in the response of either endothelial function or oxidative stress to $\mathrm{GH}$ replacement would require larger numbers of study subjects. Although current clinical practice advocates the use of dose titration GH treatment regimes, in order to limit any possible confounding effects due to $\mathrm{GH}$ dose variability, we elected to use a standard per body weight $\mathrm{GH}$ replacement regime at an accepted efficacious dose (29).

Adult GHD results in a state of volume depletion. This factor is, however, unlikely to have any effect on our measurement of FMD either before or after $\mathrm{GH}$ therapy. The stimulus of hyperaemic blood flow, which causes endothelium-dependent vasodilatation, is a local phenomenon governed by hand hyperaemia. In our study, the stimulus of hyperaemic blood flow (percentage increase from resting flow) was similar in control and GHD groups both before and after $\mathrm{GH}$ therapy.

There were no quantitative differences in lipid profiles at base line between controls and the GHD subjects, and no changes were noted following $\mathrm{GH}$ therapy. Of the measured metabolic parameters, LDLcholesterol exhibited the strongest inverse correlation with endothelial function $(r=-0.61)$ but this was not significant, probably because of the relatively small number of subjects studied. However, this observation is consistent with many other studies in which plasma LDL-cholesterol has a strong predictive value for endothelial dysfunction (30). Since there were no quantitative differences in lipids in comparison with controls or following GH replacement, the endothelial dysfunction in the GHD patients may be a consequence of qualitative differences in the LDL particles. Indeed, GHD is associated with an excess of small dense LDLcholesterol particles (7) which are particularly atherogenic (31). They exhibit an increased propensity to undergo oxidation, stimulate free radical release (32) and promote the uptake of lipids by macrophages to form foam cells, culminating in increased toxicity to endothelial cells (33). In addition, small dense LDLcholesterol particles can directly induce free radical production (34). Thus, improvement in endothelial function and reduction in oxidative stress following $\mathrm{GH}$ therapy may, in part, be due to qualitative alterations in lipoprotein particles, possibly through improvements in LDL-cholesterol metabolism, a concept supported by the observation that $\mathrm{GH}$ induces LDL receptor expression on hepatocytes (35).

Our novel observation of increased lipid-derived free radicals in adult GHD indicates a state of enhanced oxidative stress. This may contribute directly to the pathogenesis of ED, since free radicals can reduce bioavailable NO (36), are themselves directly toxic to endothelial cells (37), and facilitate the generation of toxic oxidised LDL-cholesterol particles (38). Oxidative stress may also be a consequence of ED, since dysfunctional endothelium produces excess superoxide anions (39) and NO itself has antioxidant properties. 
IGF-I stimulates NO synthesis by both endothelial cells (40) and vascular smooth muscle (41). Thus, low IGF-I levels in adult GHD may impair endothelial NO synthesis and so contribute to the pathogenesis of ED. This mechanism could also contribute to the restoration of endothelial function following GH therapy. Further support for this view comes from the observation that urinary NO metabolites are significantly reduced in GHD patients and increase significantly following 3 months of GH therapy (41). A reduction in IGF-Imediated endothelial NO synthesis may also play a role in enhanced oxidative stress in the GHD patients since NO has antioxidant properties. Thus, GH-stimulated IGF-I-mediated endothelial NO synthesis may partly account for the reduction in oxidative stress and improvement in endothelial function as a result of $\mathrm{GH}$ replacement.

The significantly higher fasting insulin levels in the presence of normal plasma glucose in the pre-treatment GHD subjects indicates a state of insulin resistance in these individuals. Impaired insulin sensitivity may contribute (directly or indirectly) to the enhanced oxidative stress and endothelial dysfunction seen in the GHD patients. Insulin resistance is associated with excess production of small dense LDL-cholesterol particles and the generation of an atherogenic lipoprotein phenotype (42) which are integrally involved in the pathophysiology of both endothelial dysfunction (43) and oxidative stress (34). Insulin resistance may also contribute directly to the excess generation of free radicals by depressing endogenous antioxidant defence mechanisms (44). Following GH replacement there was no significant improvement in insulin sensitivity, as evidenced by similar fasting insulin levels, and this may partially explain why oxidative stress still remained elevated in the GHD patients compared with controls.

GH therapy significantly improves effort tolerance, exercise capacity and increases muscle mass in GHD subjects (4). Both regular exercise and physical training in previously sedentary individuals results in increased NO synthesis and release, together with significantly improved endothelial function (45). The observed beneficial effect of GH therapy on endothelial function may thus be a consequence of the effect of $\mathrm{GH}$ on exercise capacity in these subjects. Since some reports suggest that exercise capacity is, at least partially, dependent on vascular function and NO release (46), it is possible that the described effect of GH on exercise capacity may contribute, in part, to its effect on endothelial function.

By demonstrating both endothelial dysfunction and enhanced oxidative stress in adult hypopituitary subjects with GHD, this study provides further data in support of the concept that adult GHD may be proatherogenic. This study would have benefitted from both a placebo control group and larger numbers of study subjects; however, the effect of GH replacement on both endothelial function and free radical status were internally consistent and uniformly maintained.
These data indicate that GH therapy may partially or completely reverse some of the mechanisms involved in atherogenesis and, although preliminary, provide a firm basis for further investigation.

\section{References}

1 Rosen T \& Bengtsson BA. Premature mortality due to cardiovascular disease in hypopituitarism. The Lancet 1990336 285-288.

2 Bates AS, Hoff WV, Jones PJ \& Clayton RN. The effects of hypopituitarism on life expectancy. Journal of Clinical Endocrinology and Metabolism 199681 1169-1172.

3 Binnerts A, Duerenberg P, Swart GR, Wilson JHP \& Lamberts SWJ. Body composition in growth hormone deficient adults. American Journal of Clinical Nutrition 199255 918-923.

4 Cuneo RC, Salomon F, Wiles CM, Hesp R \& Sonksen PH. Growth hormone treatment in growth hormone deficient adults. I. Effects on muscle mass and strength. II. Effects on exercise performance. Journal of Applied Physiology 199170 688-694 \& 695-700.

5 Johansson JO, Fowelin J, Landin K, Lager I \& Bengtsson BA. Growth hormone deficient adults are insulin resistant. Metabolism $199544434-437$.

6 Russell-Jones DL, Watts GF, Weissberger A, Naoumova R, Myers J, Thompson GR et al. The effect of GH replacement on serum lipids, lipoproteins, apolipoproteins and cholesterol precursors in adult GHD patients. Clinical Endocrinology 199441 345-350.

7 O'Neal D, Few FL, Sikaris K, Ward G, Alford F \& Best JD. Low-density lipoprotein particle size in hypopituitary adults receiving conventional hormone replacement therapy. Journal of Clinical Endocrinology and Metabolism 199681 24482454.

8 Al-Shoumer KAS, Cox KH, Hughes CL, Richmond W \& Johnston DG. Fasting and post-prandial lipid abnormalities in hypopituitary women receiving conventional hormone replacement therapy. Journal of Clinical Endocrinology and Metabolism 199782 26532659.

9 Carrol V, Christ ER, Bengtsson BA, Christiansen JS, Clemmons D, Hintz $\mathrm{R}$ et al. GH deficiency in adulthood and the effect of GH replacement. Journal of Clinical Endocrinology and Metabolism $199883382-395$.

10 Wenmalm A. Nitric oxide (NO) in the cardiovascular system: role in atherosclerosis and hypercholesterolaemia. Blood Pressure $19945279-282$.

11 Jessup W. Oxidised lipoproteins and nitric oxide. Current Opinion in Lipidology $19967274-280$.

12 Henderson A. Endothelium in control. British Heart Journal 1991 $65116-125$.

13 Celermajer D, Sorenson K, Gooch V, Spiegelhalter D \& Deanfield J. Non-invasive detection of endothelial dysfunction in children and adults at risk of atherosclerosis. The Lancet 1992340 1111-1115.

14 Kerr ME, Boundr LM \& Monti EJ. An introduction to oxygen free radicals. Heart and Lung 199625 200-209.

15 Yagi K. Lipid peroxides and human diseases. Chemistry Physiology Lipids 198745 337-342.

16 Cannon RO. Role of nitric oxide in cardiovascular disease. Clinical Chemistry 199844 1809-1819.

17 Kostner K, Hornykewycz S, Yang P, Neuntful T, Eeidinger F, Mourer $\mathrm{G}$ et al. Is oxidative stress causally linked to unstable angina pectoris? A study of $100 \mathrm{CAD}$ patients and matched controls. Cardiovascular Research 199736 330-336.

18 Ferrari R, Arolletti L, Commini L, Gavia G, Cargnomi A, Curello S et al. Oxidative stress during myocardial ischaemia and heart failure. European Heart Journal 199819 Suppl B B2-B11.

19 Ramsey M, Goodfellow J, Jones C, Luddington L, Lewis M \& Henderson A. Endothelial control of arterial distensibility is impaired in chronic heart failure. Circulation 199592 3212-3219. 
20 Ashton T, Rowlands CC, Jones E, Young IS, Jackson SK, Davies B et al. Electron spin resonance spectroscopic detection of oxygencentred radicals in human serum following exhaustive exercise. European Journal of Applied Physiology 199877 498-502.

21 Tortolani AJ, Powell SR, Misik V, Weglicki WB, Pogo GJ \& Kramer JH. Detection of alkoxyl and carbon-centred radicals in coronary sinus blood from patients undergoing elective cardioplegia. Free Radicals Biology and Medicine 199314 421-426.

22 Grech ED, Dodd NJF, Jackson MJ, Morrison WL, Faragher EB \& Ramsdale DR. Evidence for free radical generation after primary percutaneous transluminal coronary angioplasty recanalization in acute myocardial infarction. American Journal of Cardiology $199677122-127$.

23 Allain CC, Poon LS, Chan CSG, Richmond W \& Fu PC. Enzymatic determination of total serum cholesterol. Clinical Chemistry 1974 20 470-475.

24 Wahlefeld AW. Triglycerides. Determination after enzymatic hydrolysis. In Methods of Enzymatic Analysis, pp 1831-1835. Ed. HU Bergmeyer. New York: Verlag Chemie Weinheim, Academic Press Inc., 1974.

25 Warnick GR, Nguyen T \& Albers AA. Comparison of improved precipitation methods for quantification of HDL cholesterol. Clinical Chemistry 198531 217-222.

26 Friedewald WT, Levy RL \& Fredrickson DS. Estimation of the concentration of LDL cholesterol without use of the preparative ultracentrifuge. Clinical Chemistry 197218 499-502.

27 Bang P, Eriksson U, Sara V, Wivall IL \& Hall K. Comparison of acid ethanol extraction and acid gel filtration prior to IGF-I and IGF-II radioimmunoassays: improvement of determinations in acid ethanol extracts by the use of truncated IGF-I as radioligand. Acta Endocrinologica 1991124 620-629.

28 Berkenboom G, Gresset V, Giot C, Unger P, Vachiery JL \& LeClerc JL. Endothelial function of internal mammary artery in patients with coronary artery disease and in cardiac transplant patients. American Heart Journal 1998135 488-494.

29 de Boer H \& van der Veen H. Guidelines for optimizing growth hormone replacement therapy in adults. Hormone Research 1997 48 Suppl 5 21-30.

30 Voors AA, Oosterga M, Buehema H, May JF, Grandjean JG, Van-buten A et al. Dyslipidaemia and endothelium dependent function in internal mammary arteries used for coronary bypass surgery. Cardiovascular Research 199734 568-574.

31 Austin MA, Breslow JL, Hennekens CH, Buring JE, Willett WC \& Krauss RM. Low density lipoprotein subclass patterns and the risk of myocardial infarction. Journal of the American Medical Association $19882601917-1921$.

32 Steinberg D, Parthasarathy S, Carew TE, Khoo JC \& Witztum JL. Beyond cholesterol: modifications of LDL that increase its atherogenicity. New England Journal of Medicine 1989320 915-924.

33 Galle J. Impairment of endothelium-dependent dilatation in rabbit renal arteries by oxidised LDL. Circulation 199592 1582-1589.
34 Harrison DG \& Ohara Y. Physiologic consequences of increased vascular oxidant stress in hypercholesterolaemia: implications of impaired vasomotion. American Journal of Cardiology 199575 75B-81B.

35 Paronini P, Angelin B, Lobie PE, Norstedt G \& Rudling M. Growth hormone specifically stimulates the expression of LDL receptors in human hepatoma cells. Endocrinology 1995136 3767-3773.

36 Lynch SM, Frei B, Morrow JD, Roberts LJ 2nd, Xu A, Reyna R et al. Vascular superoxide dismutase deficiency impairs vasodilator function through direct inactivation of nitric oxide and increased lipid peroxidation. Arteriosclerosis, Thrombosis and Vascular Biology $1997112975-2981$.

37 Jacob AK, Hotchkiss RS, DeMeester SL, Hiramatsu M, Karl IE, Swanson PE et al. Endothelial cell apoptosis is accelerated by inorganic iron and heat via an oxygen radical dependent mechanism. Surgery 1997122 243-253.

38 Steinbrecher P, Zhang HF \& Lougheed M. Role of oxidatively modified LDL in atherosclerosis. Free Radicals Biology and Medicine 19909 155-168.

39 Harrison DG. Endothelial function and oxidant stress. Clinical Cardiology 199720 Suppl 2 II-11-7.

40 Tsukahara H, Gordienko DV, Tonshof B, Gelato MC \& Goligorsky MS. Direct demonstration of insulin like growth factor-I-induced nitric oxide production by endothelial cells. Kidney International $199445598-604$.

41 Boger RH, Skamira C, Bode-Buger SM, Brabant G, von zur Muhlen A \& Frolich JC. Nitric oxide may mediate the haemodynamic effects of recombinant human $\mathrm{GH}$ in patients with acquired GHD. Journal of Clinical Investigation 199698 2706-2713.

42 Despres JP. Dyslipidaemia and obesity. Balliere's Clinical Endocrinology and Metabolism 1994 8 629-653.

43 Saltar N, Petrie JP \& Jaap JA. The atherogenic lipoprotein phenotype and vascular endothelial dysfunction. Atherosclerosis $1998138229-235$.

44 Foure P, Rossini E, Lafond JL, Richard MJ, Favier A \& Halimi S. Vitamin E improves the free radical defence system potential and insulin sensitivity of rats fed high fructose diets. Journal of Nutrition 1997127 103-107.

45 Bones C, Bellamy M, Brownlee M, Goodfellow J, Ramsey MW, Lewis MJ et al. Endothelial function in healthy young adults is rapidly improved by physical training. European Heart Journal 199718265.

46 Nieubauer J \& Cooke JP. Cardiovascular effects of exercise: role of endothelial shear stress. Journal of the American College of Cardiology 199628 1652-1660.

Received 19 July 1999

Accepted 22 November 1999 